\title{
El neoliberalismo como teología política. Habermas, Foucault, Dardot, Laval y la historia del capitalismo contemporáneo
}

\section{José Francisco Desentis-Torres}

Magister en Estudios Latinoamericanos. Licenciado en Economía

Universidad Nacional Autónoma de México. Ciudad de México, México

https://orcid.org/0000-0002-3070-2578・f.desentis08@gmail.com

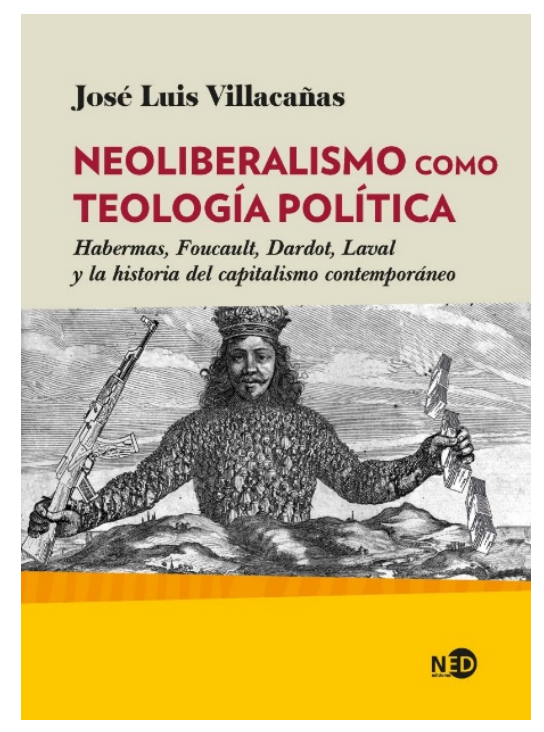

Villacañas, José Luis.

Neoliberalismo como teología

política. Habermas, Foucault,

Dardot, Laval y la historia del

capitalismo contemporáneo.

Barcelona: Ned ediciones

ISBN 978-84-18273-01-8

2020

280 págs.

José Luis Villacañas, catedrático de Filosofía en la Universidad Complutense de Madrid, establece un diálogo temático con los pensadores franceses Pierre Dardot y Christian Laval a propósito de sus análisis críticos sobre el neoliberalismo (Dardot y Laval, 2013, 2015; Laval, 2020). El diálogo se produce desde una lectura subterránea e imbricada del diagnóstico de la crisis del capitalismo tardío de Jürgen Habermas y la definición de biopolítica de Michel Foucault. El objetivo de Villacañas es "ofrecer un tipo ideal del neoliberalismo que pueda ser reconocido en su coherencia lógica e ideológica” (p. 9). Los contenidos temáticos del libro son fundamentalmente tres: a) la experiencia europea

Recibido: 05/08/2021 | Aprobado: 24/10/2021 | Publicado: 01/01/2022

(c) (1) @(2) Esta obra está bajo una Licencia Creative Commons Atribución-NoComercialCompartirIgual 4.0 Internacional.

\section{¿Cómo citar este artículo? / How to quote this article?}

Desentis-Torres, J. F. (2022). El neoliberalismo como teología política. Habermas, Foucault, Dardot, Laval y la historia del capitalismo contemporáneo. Prospectiva. Revista de Trabajo Social e intervención social, (33), 335-340. doi: 10.25100/ prts.v0i33.11509. 
Desentis-Torres

contemporánea respecto a la ideología neoliberal (capítulos 1-3); b) la definición del neoliberalismo como dispositivo de dominación y de gobierno de los seres humanos (capítulos 4 y 5); y c) las alternativas futuras al neoliberalismo (capítulo 6).

El primer capítulo comenta Problemas de legitimación en el capitalismo tardío de Habermas (1989) en calidad de primer diagnóstico sobre la crisis de gubernamentalidad del capitalismo del Estado de Bienestar, fordista e industrial. Aunque enmarcado en una polémica con la "teoría de los sistemas" de Niklas Luhmann (1984), el libro impulsa el desarrollo de la "teoría de la evolución social". La tesis de Villacañas es: "El neoliberalismo debe ser entendido como la solución temporal a los problemas de legitimidad del capitalismo tardío tal y como lo planteaba Habermas" (p. 33). En términos generales, el análisis habermasiano identifica la tensión entre "sistemas sociales" autogobernados y "mundo de la vida" extrasistémico en las condiciones del capitalismo regulado por el Estado: “Cuanto más se dominaba genéricamente la naturaleza exterior, más exigencias de individuación planteaba la naturaleza interior, más resistencias elevaba el individuo singular ante el gobierno" (pp. 19-20). La conclusión de Habermas es que los "psiquismos" juegan un papel de ambiente y elementos del sistema y, por lo tanto, si no se gobiernan adecuadamente (con un nuevo "principio de organización" y "motivación"), ponen en jaque la legitimad del autogobierno del sistema. Sin embargo, el límite de la teoría habermasiana es la ausencia de la cuestión de la técnica. Como sí lo vislumbra Hans Blumenberg (2013), el mundo de la vida no se despliega exclusivamente por "integración", sino también por "tecnificación". La abstracción y virtualidad de la técnica organizadora de los mundos de la vida pudo engarzar con una "colonización del interior del psiquismo" a través del a priori del mercado, el dinero y el poder. La "solución neoliberal" del Homo economicus se convierte en el nuevo principio del sistema psíquico donde la rentabilidad mercantil se presenta como la "motivación trascendental" del mundo de la vida.

El segundo capítulo comenta El nacimiento de la biopolítica de Foucault (2007) como descripción del inicio del nuevo "poder pastoral" ejercido por la "vinculación universal del mercado". Para Villacañas esta obra es una suerte de respuesta al análisis habermasiano ya que la "biopolítica neoliberal" es, precisamente, la solución al problema de legitimación del capitalismo tardío: “Era el gobierno de la subjetividad en un contexto que ya se había desprendido de toda dimensión valorativa y normativa, de todo anclaje en el mundo de la vida tradicional, de toda pretensión universalista de identidad y pertenencia" (p. 38). La cuestión de la "motivación" se transforma en una naturalización del Homo economicus, esto es, en una interiorización psíquica de las reglas de la economía liberal. Lo específico de la biopolítica neoliberal consiste en que ahora el escenario interno del psiquismo converge con las instancias externas del poder y del gobierno sin necesidad de una mediación política. Se trata de una "simple política de las cosas" que presupone una armonía en las leyes manejadas tanto por las agencias mundiales como por los individuos. La racionalidad formal de la competencia se ejerce onmes et singulatim, se pierde la identidad en el mundo 
Desentis-Torres

de la vida, se minusvalora la acción comunicativa y se acrecienta la despolitización. El límite de Foucault radica en que vincula desmedidamente el análisis del neoliberalismo con el de los liberalismos clásicos y por ello no puede captar su radical novedad: "Una revolución civilizatoria integral, una nueva etapa de la humanidad, que sustituía el esquema del industrialismo y el fordismo vigente desde finales del siglo XIX" (p. 35).

El tercer capítulo atiende panorámicamente la experiencia neoliberal de Europa. Villacañas (2020) señala, siguiendo a Foucault, que el capitalismo no es una estructura económica autónoma, sino un sistema que se encuentra atravesado por un sistema de gobierno, a su vez, sostenido por una "teoría de la verdad y del poder", esto es, "hegemonía". Por tal motivo, para entender el neoliberalismo es preciso prestar atención a fenómenos históricos como el pacto Mao-Nixon de 1972 cuyo efecto fue impulsar una nueva fase de globalización; y, asimismo, se debe considerar la incorporación de China al capitalismo. El argumento del filósofo valenciano es que desde este contexto habría que interpretar lo que sucedió en Europa, particularmente, la decisión geoestratégica de la integración económica: “La cuestión nueva era el posicionamiento de Europa en una situación mundial de globalización comercial [...] Europa se entregó así a una guerra por otros medios, el de la competencia" (pp. 59-60). Villacañas concluye que el neoliberalismo à la europea desencadenó una desigualdad donde países como Alemania, en tanto principal exportador de nivel mundial, cuenta con superávit en sus balances contables, mientras otros países del sur presentan desequilibrios fiscales, endeudamiento público y poca productividad.

El cuarto capítulo es el argumento central del libro puesto que entra propiamente en la interpretación del neoliberalismo como teología política. En términos sucintos, Villacañas define la teología política como "el nombre para la reunificación, con aspiraciones de totalidad, de la división de poderes que, de un modo u otro, fue constitutiva de Occidente desde la irrupción del judaísmo y el cristianismo como religiones mundiales" (p. 75). Es, pues, el intento de superación del dualismo de los poderes político y religioso a través de la imposición de un régimen teórico-práctico unitario. Históricamente algunos gestos de teología política han sido las luchas entre el papado y el imperio durante la Edad Media, las luchas por la construcción de Iglesias nacionales en la modernidad temprana, la organización westfaliana, entre otros. Teóricamente, por su parte, fueron el Leviatán de Thomas Hobbes y la obra de Carl Schmitt. En la actualidad, afirma Villacañas, “el neoliberalismo es la última voluntad inspirada por esta pretensión de totalidad, y de absorción de todos los poderes [...] pero desplegando su voluntad de forma completamente ajena a las viejas fórmulas comunitarias compactas" (p. 83). El "gobierno pastoral biopolítico" del neoliberalismo impone como norma existencial una coincidencia de la vida personal y de la totalidad social, un gobierno total basado en una configuración de la subjetividad y la objetividad según las leyes de la competitividad económica. El neoliberalismo se desenvuelve con una aspiración hegemónica de edificar un poder 
Desentis-Torres

mundial único a pesar de su constitución gubernamental fragmentada en múltiples Estados; y éstos, por su parte, desempeñan la nueva función de ponerse al servicio del poder mundial.

De manera sugerente Villacañas señala que la ética del Homo economicus neoliberal no es nueva, sino que, en realidad, comparte múltiples gestos con la ética del Homo religiosus puritano. La especificidad del giro inscrito por el neoliberalismo se juega en el despojo de todo sentido religioso trascendente de tal modo que "la persecución de riqueza adquiere ahora el carácter de un deporte" (p. 119). A través del elemento psíquico del goce se encuentra un modo de repetir ad infinitum esta nueva "motivación" del mundo de la vida: "Cada uno podía disponer de su goce ejercitándose en la competencia" (p. 120). Y, a su vez, la dimensión religiosa de la "salvación" se desplaza por un reforzamiento extremo del principio del goce con una estructura homóloga: el plusvalor. "Así se dio con lo que Lacan llamó el plus-de-goce" (Ibidem). Con ello el neoliberalismo inscribe en el psiquismo una lógica de rendimientos crecientes aplicada al principio de placer. El paso decisivo que, a juicio de Villacañas, permite la realización hegemónica del neoliberalismo es el mismo que consolida la efectivización de un capitalismo autoconsciente, "un capitalismo basado en un deseo autoconsciente de capitalismo" (p. 124). La sobredeterminación de todas las esferas de la vida humana a partir de la economía se da cuando "el sentido último del nuevo hombre ahora es lograr una capitalización de sí mismo" (p. 128). En el neoliberalismo "el capitalismo es el Otro", una "trascendencia inmanente" donde hay teología sin teología y política sin política: "La dimensión infinita del símbolo es sustituida por la indefinida interpretación del principio del placer por parte del mercado" (p. 162).

El capítulo quinto complementa el análisis del capítulo anterior al ofrecer una interpretación de la "ontología del presente" a partir de la cuestión de las vidas precarias. Villacañas entiende por vida precaria un sentido profundo de existencia adaptada a la "representación del capitalismo como naturaleza" (p. 185). El "absolutismo de la realidad" del capitalismo se presenta al mundo de la vida como evidencia o sobreentendido incuestionable. Se trata de una "aleturgia constituida" en la que los humanos gozan del mundo en condiciones de plena tecnificación y virtualización: "Con ello se cumple la reducción de biopolítica a economobiopolítica" (p. 185). La temporalidad del consumo inscribe un dominio del instante, un "lento presente" o "latencia" completamente ajena a cualquier tipo de reflexividad. El "fatalismo de la facticidad" neoliberal reduce la historia a mera obligación evolutiva donde no existe apertura hacia mundos de la vida alternativos. Asimismo, esta ontología del presente se sirve de una administración de la pulsión de muerte como "terror", esto es, "la producción de un miedo sin otra esperanza que el plusde-goce, un miedo compacto, macizo, desesperado, para el que la vida que resta es pura inercia" (p. 194). En suma, se trata de una destrucción de la subjetividad que, a nivel público, adquiere manifestaciones como la del "populismo reaccionario". 
Desentis-Torres

El sexto y último capítulo entra en diálogo más directamente con las ideas de Dardot y Laval en torno al libro Común. Una vez reconocido que la historicidad del neoliberalismo no ha terminado y que, en esencia, es de naturaleza política y no sólo económica puesto que su dominio gira alrededor del poder, Villacañas sentencia con Foucault que la cuestión de nuestros tiempos contemporáneos es la siguiente: "no habrá forma de separarnos del neoliberalismo si no encontramos un arte de gobierno alternativo" (p. 207). El reto es pensar un sistema distinto que no quede preso de la tentación de la teología política. En opinión del filósofo valenciano, el reto no puede solucionarse favorablemente si no se aspira a fomentar una pluralidad de motivaciones en el "cuidado de sí", esto es, un trabajo simbólico que se manifieste en una "reinvención de nosotros mismos" $\mathrm{y}$, por lo tanto, se generen espacios para una libertad no consignada en el mercado: "Esto implica salvar la libertad de una universidad pública, sin la que no será posible conquistar motivaciones simbólicas capaces de reinventarnos sin pasar por el mercado" (p. 208). Siguiendo a Dardot y Laval, Villacañas apuesta por la creación de una nueva institucionalización fundada en la idea de "lo común" y los "valores republicanos" en el nivel de los mundos de la vida, pero además suplementada con la noción de "cooperativa de productores": "Sólo ahí veo una atención responsable a la realidad económica que a la vez no se deje conquistar por el Homo economicus" (p. 241). Finalmente, alejándose del sabor antiestatalista de los pensadores franceses, Villacañas afirma que es preciso apelar tanto a nuevos marcos legales e institucionales como a "un cambio radical en el control centralizado del Estado" (p. 243).

El libro finaliza con un Post scriptum a propósito del inicio de la pandemia de Covid19. Dejando de lado su argumento sobre la construcción de un "pueblo europeo", cabe destacar su convicción de que "la realidad no va a cambiar por el Covid-19" (p. 251), sino por la intervención de sujetos políticamente comprometidos cuyo objetivo sea la construcción de un "nuevo republicanismo" que defienda la "comunidad de la vida" de manera incondicional, particularmente, a través de la exigencia de un sistema productivo cuyo fundamento sea la "soberanía sanitaria" (p. 256).

A modo de conclusión podemos indicar que el/la lector/a puede encontrar en Neoliberalismo como teología política un doble análisis crítico de la "biopolítica neoliberal", de un lado, una interpretación de las determinaciones y límites constitutivos del "goce neoliberal" y, de otro lado, una proposición de posibles vías alternativas a éste. La insistencia en que el neoliberalismo se trata esencialmente de una estructura política al nivel del "mundo de la vida" sirve de complemento a los estudios económico-políticos que, sin negar tal determinación, se concentran en mostrar la especificidad neoliberal en el ámbito de los "sistemas de gobierno". 
Desentis-Torres

\section{Referencias bibliográficas}

Blumenberg, H. (2013). Historia del espíritu de la técnica. Valencia, España: Pre-Textos.

Dardot, P., y Laval, C. (2013). La nueva razón del mundo. Ensayo sobre la sociedad neoliberal. Barcelona, España: Gedisa.

Dardot, P., y Laval, C. (2015). Común. Ensayo sobre la revolución en el siglo XXI. Barcelona, España: Gedisa.

Foucault, M. (2007). El nacimiento de la biopolitica. Buenos Aires, Argentina: Fondo de Cultura Económica.

Habermas, J. (1989). Problemas de legitimación en el capitalismo tardío. Madrid, España: Cátedra.

Laval, C. (2020). Foucault, Bourdieu y la cuestión neoliberal. Barcelona, España: Gedisa.

Luhmann, N. (1984). Sistemas sociales. Barcelona, España: Anthropos-UIA-CEJA.

Villacañas, J. L. (2020). Neoliberalismo como teología política. Habermas, Foucault, Dardot, Laval y la historia del capitalismo contemporáneo. Barcelona, España: Ned ediciones. 